Teknokultura. Revista de Cultura Digital y Movimientos Sociales

ISSNe: $1549-2230$

http://dx.doi.org/10.5209/tekn.64712

\title{
Nuevas formas de consumo 3.0. El retorno del sujeto al algoritmo
}

\author{
Víctor Riesgo Gómez²
}

Recibido: 14 de junio 2019 / Aceptado: 30 de diciembre 2019 Open peer reviews

Resumen. Se realiza un somero repaso a la evolución conceptual y metodológica de la sociología del consumo. Se identifican los puntos en común de esta evolución con los cambios ocurridos en el sistema productivo. Posteriormente se analizan los nuevos tipos de consumo derivados de la transformación tecnológica que ha tenido lugar en el nuevo ecosistema digital, para finalmente realizar algunas reflexiones derivadas del análisis producido.

Palabras clave: algoritmos predictivos; internet; redes sociales; sharing economy; sociología del consumo.

\section{[en] New forms of consumption 3.0. The return of the subject to the algorithm}

\begin{abstract}
A brief review of the conceptual and methodological evolution of the sociology of consumption is carried out. The common points of this evolution are identified with the changes in the production system. Subsequently, the new types of consumption derived from the technological transformation that has taken place in the new digital ecosystem are analyzed, to finally make some reflections derived from the analysis produced.
\end{abstract}

Keywords: internet; predictive algorithms; sharing economy; social networks; sociology of consumption.

Sumario. 1. Introducción. 2. Consumidores, seres sociales. 3. La crisis de un modelo. 4. Nuevas tecnologías e internet. 5. Prosumidores colaborativos produciendo reputación. 6. Produsarios produciendo contenidos y datos. 7. Reflexiones finales. 8. Referencias.

Cómo citar: Riesgo Gómez, V. (2020). Nuevas formas de consumo 3.0. El retorno del sujeto al algoritmo. Teknokultura. Revista de Cultura Digital y Movimientos Sociales, 17(1), 3-11.

\section{Introducción}

Partimos del repaso sucinto de algunas aportaciones en perspectiva histórica de la sociología para facilitar la comprensión del consumo en las sociedades industriales. Nos centramos en concreto en algunas reflexiones teóricas sobre la noción de necesidad y la estrecha relación existente entre los conceptos de producción y consumo.

A continuación, señalamos algunos fenómenos novedosos surgidos a consecuencia de las transformaciones en el orden económico, cultural y tecnológico en un contexto cuyos límites están aún por definir. De esta indefinición da fe la proliferación de términos entre los que encontramos, sin ánimo de exhaustividad, algunos como "capitalismo de plataformas" (Srnicek, 2018), "capitalismo de vigilancia" (Zuboff, 2019), "neofeudalismo digital" (Morozov, 2018) o "postcapitalismo" (Mason, 2016). Más allá del debate terminológico, parece evidente que la centralidad del uso de internet ha provocado cambios significativos en ambas esferas, producción y consumo, a la vez que modificaba la propia noción de nece- sidad. Este trabajo se centra específicamente en dos cuestiones, la elaboración de sistemas de reputación online en el seno de las economías colaborativas mediadas por plataformas tecnológicas y los procesos de producción, recopilación y valorización de datos de diversos tipos en el ecosistema digital. Con ello se muestran aspectos concretos de cómo se difuminan aún más los límites entre producción y consumo y se expande el campo de necesidades.

Finalmente planteamos la utilidad para la sociología del consumo de incluir en sus observaciones, con los matices necesarios para adaptarse al fenómeno, estas nuevas prácticas de consumo en el contexto novedoso y en formación de la cuarta revolución industrial.

\section{Consumidores, seres sociales}

Gracias a las aportaciones de la sociología del consumo (Alonso, 2005; Arribas, 2013; Bourdieu, 2012; López de Ayala, 2004; Veblen, 2004) parece generalmente aceptado el hecho de que las decisio-

\footnotetext{
Financiación FPI - Universidad Nacional de Educación a Distancia

Universidad Nacional de Educación a Distancia (España)

E-mail: vriesgo@poli.uned.es 
nes de consumo son influidas por un gran número de cuestiones. Con ello se desbordaba un supuesto comportamiento racional del consumidor, orientado a maximizar sus beneficios y satisfacer apetitos forjados, casi en exclusiva, como consecuencia de necesidades objetivas (Alonso, 1986). Frente a esta perspectiva la sociología del consumo introdujo en la explicación diferentes factores, de tipo cultural, simbólico, identitario o de clase, contemplando por tanto el consumo como "un hecho social total (...) realidad objetiva y material, pero es, a la vez, e indisolublemente, una producción simbólica" (Alonso, 2004, p. 8).

En primer lugar, el propio término de necesidad sería bastante más problemático de lo que a primera vista podría parecer (Alonso, 1986; Naredo, 2015, p. 88). Al intentar ahormar las necesidades bajo la propuesta piramidal del psicólogo Abraham Maslow encontramos un cierto grado de ambigüedad e indefinición, pues buena parte de ellas "solo pueden satisfacerse a través de un mecanismo social, por ejemplo, el mercado, [por lo que] dejan de tener cualquier autonomía biológica para convertirse inmediatamente en necesidades sociales". (Alonso, 1986, p. 28). Pero no solo en su satisfacción encontramos la presencia de mecanismos sociales. También el mismo proceso de formación de las necesidades resulta influido social y culturalmente. Por ejemplo, por medio de la publicidad se potenciarían otros motores impulsores del consumo. Así, "bienes superfluos, marcados antes por el deseo que la necesidad (...) se presentan como imágenes socialmente producidas, símbolos de estatus y de pertenencia a grupos, con los que es forzoso identificarse para promocionar o simplemente instalarse" (Ortí, 1986, p. 187). En la génesis de estos deseos y en su misma legitimidad, podemos encontrar rastros de un tipo de lucha de clases implícita, pues generalmente son las clases que atesoran mejores posiciones sociales quienes gozan de mayor capacidad para dictar los bienes socialmente aceptables o, lo que es lo mismo, los consumos dignos de ser deseables, como ya mostró Veblen (2004) o más recientemente Bourdieu (2012), a través principalmente del "efecto de demostración de estatus" (Alonso, 1986, p. 28).

Un segundo aspecto que también conviene considerar es que el consumo sería la otra cara de la moneda de la producción. Podemos pensar que la producción está dirigida a satisfacer la demanda de bienes de consumo en una sociedad dada en la que los consumidores soberanos crean en base a sus necesidades una determinada estructura de preferencias. Para estimular su formación las técnicas persuasivas puestas al servicio del marketing y la publicidad contribuyen a difundir un discurso ideológico (De Lucas, 2013), funcional para que esas mercancías, resultado del sistema productivo, encuentren comprador. A esto cabe sumar un desplazamiento progresivo desde el hogar, como lugar orientado al autoabastecimiento, hacia el mercado como espacio donde aprovisionarse de cada vez más bienes a precios asequibles (Braverman, 1975) La interacción de publicidad y condiciones de posibilidad desarrolladas en el industrialismo fordista ayudan a constituir "la norma social del consumo de masas" (Aglietta, 1979). La expansión del sistema productivo conllevaba una expansión paralela del consumo capaz de absorber ese excedente. Sin el desarrollo en paralelo del consumo hubiera sido impensable tal incremento de la producción como el que se dio en ese periodo histórico. Braverman (1975) o Polanyi (2003) señalan el papel que juega la separación de las clases trabajadoras de los modos tradicionales de producción y por ende de los modos de consumo que los acompañaban. Así, separados de los distintos lazos sociales propios de comunidades orientadas a la autosatisfacción de las necesidades "los trabajadores se ven forzosamente atados al capitalismo por el consumo individual de mercancías resultantes de la producción en masa" (Aglietta, 1979, p. 131).

A afianzar la norma de consumo de masas contribuyó la inclusión y el reconocimiento por parte de los Estados occidentales de los derechos sociales (Marshall, 1997). Así, a la vez que se integraba a las clases obreras en el sistema político a través del concepto de ciudadanía, la implantación del Estado de bienestar contribuía al crecimiento económico y al aumento del consumo, garantizando la provisión de una serie de recursos básicos, dando lugar de este modo a treinta años de crecimiento económico, pleno empleo y satisfacción creciente de las demandas sociales canalizadas en buena medida a través de incrementos en los niveles de consumo.

\section{La crisis de un modelo}

A finales de los años sesenta, y especialmente en la década de los setenta, el conjunto de factores impulsores del crecimiento económico muestra signos de agotamiento, inaugurándose así un periodo de crisis singular. En ese contexto de crisis se forja el auge de una nueva concepción respecto a la razón que organiza el mundo. Los consensos de posguerra establecidos de manera tácita en el bloque occidental son cuestionados. Nacía un nuevo orden neoliberal, que combinaba la imposición de recetas orientadas a estimular el crecimiento económico (Harvey, 2007), con cambios de tipo cultural e ideológico (Dardot y Laval, 2013; Foucault, 2007). Se inicia un declive de buena parte de los elementos articuladores que daban sentido a la norma del consumo de masas de Aglietta, o al menos asistimos a su transformación (Alonso, 2004).

En el campo de la sociología del consumo también encontramos una adaptación al nuevo contexto. En un modelo de economía postfordista el concepto de clase social pierde poder explicativo y es cuestionado por ideas como individualización y diversificación (Beck, 1998, p. 102). Tal cuestionamiento no conlleva finiquitar en términos materiales y efectivos las clases sociales como categorías sociológicas válidas que sirvan para ayudar a explicar la desigual distribución de recursos en un contexto de capitalismo tardío. Más 
bien al contrario, el concepto de clase contribuye definitivamente a entender diferentes dimensiones de la desigualdad (Goldthorpe, 2012), y, especialmente al calor de un conjunto de transformaciones en los ámbitos de las relaciones de producción, existen algunas evidencias de la emergencia de nuevas infraclases en el seno de las sociedades occidentales integradas por individuos que, dotados de ciertos capitales culturales, no encuentran condiciones objetivas óptimas en las que poner en valor este capital y se ven obligados a transitar por trayectorias laborales y vitales caracterizadas por situaciones de mercado y trabajo fuertemente precarizadas (Standing, 2013). Por ello, en términos marxianos, más que la desaparición de la clase en sí, estaríamos ante el debilitamiento de la clase para sí, es decir, de la condición de la clase como proveedora de identidad. Como consecuencia de ello estaríamos ante una cierta reinterpretación singular y particular de los signos y símbolos procedentes de los distintos elementos que estimulan el consumo. "El consumo destaca como fuente para la construcción del yo" (López de Ayala, 2004, p. 174). Igualmente, las relaciones entre consumo y producción son interpretadas mediante un marco dialéctico, los consumidores reciben infinidad de estímulos orientados a incrementar las ventas de productos asociándolos a ciertos significados que apelan a estas construcciones de identidad. Sin embargo, lejos de actuar como recipientes vacíos en los que es fácil introducir cualquier construcción social, estos mismos consumidores llevan a cabo procesos de reinterpretación y adaptación de los significados procedentes de la publicidad y los medios de comunicación a sus propias condiciones materiales de existencia y los marcos culturales en que se desenvuelven, remitiendo, en definitiva, al $h a$ bitus de Bourdieu (2012).

En paralelo la producción se modifica, quedando inmersa en procesos de flexibilización, segmentación, fragmentación o diferenciación (Alonso, 2004). Siguiendo con Alonso (2005), esta modificación se da como consecuencia del agotamiento en todas sus dimensiones del modelo iniciado en el periodo de posguerra. El capitalismo de consumo (Alonso, 2005 , p. 60) inicia su declive como consecuencia de la confluencia de un conjunto de problemas. La transformación tecnológica y el incremento de la robotización se suman a transformaciones en las relaciones laborales y salariales, a la conciencia sobre crisis energética y ambiental en su conjunto o al cuestionamiento cada vez mayor del Estado de bienestar. El modelo de regulación propio de la norma del consumo de masas es sustituido a partir de los años ochenta del pasado siglo por un nuevo contexto económico y social "en el que el horizonte no es ya tanto un capitalismo industrial y material como un capitalismo financiero, virtual e inmaterial" (Alonso, 2005 , p. 65). Es precisamente en este nuevo marco globalizador y altamente flexibilizado donde cobran especial relevancia las nuevas tecnologías de la información y la comunicación como soporte y condición de posibilidad para su expansión y consolidación. De ello nos ocupamos en el siguiente apartado.

\section{Nuevas tecnologías e internet}

En este contexto de transformación profunda de las fuentes de rentabilidad del capital, iniciada tras la crisis de los años setenta del pasado siglo, decae la importancia de los procesos productivos tradicionales centrados en la gran industria, y emerge un nuevo nicho de negocio donde parte del crecimiento se debió al desarrollo de las tecnologías de la información y la comunicación. Impulsado en gran medida por fuertes inversiones públicas, tanto en lo que se refiere a software y hardware (Mazzucato, 2014), como en el despliegue de las infraestructuras que sirvieron de soporte físico para su desarrollo: cables submarinos, fibra óptica, servidores y bases de datos... (Srnicek, 2018), este sector económico no dejó de crecer, salvo durante el periodo en el que se pincha lo que se denominó la burbuja puntocom.

Debemos entender internet, antes que como un producto acabado en sí, como un hito más en un proceso en el que convergen multitud de factores transformadores (Briggs y Burke, 2002; Castells, 2011; Keen, 2016; Sadin, 2018) y a partir del cual emergen diversos cambios (Carr, 2011; Castells, 2011; MayerSchönberger y Cukier, 2013; Rikfin, 2014). La consolidación de la red añade una serie de potencialidades operando de manera conjunta. La comunicación instantánea y descentralizada proporciona gran cantidad de información que es almacenada de manera cada vez más exhaustiva y eficiente. Los continuos avances en computación facilitan a su vez el procesamiento automatizado de esta información (Dujarier, 2016). Estos factores generan nuevos mercados indisolublemente asociados a nuevos consumos y espacios de producción.

En el campo del consumo aparecen una gran cantidad de utensilios, desde los primeros ordenadores personales con los que acceder a la red, hasta la multiplicación de dispositivos electrónicos como teléfonos inteligentes, tabletas o un sinfín de gadgets en constante renovación ${ }^{3}$. Para constituir esto como nueva necesidad surge una oferta creciente de productos culturales, algunos de los cuales producidos y consumidos en red. El tiempo empleado en el espacio virtual no paró de crecer, en parte dedicado a construir identidades individuales utilizando plataformas virtuales. Cada vez más personas producían contenidos, comunicándose con cualquier parte del globo sin demasiadas dificultades y consumían productos que hasta entonces habían sido impensables sin desplazarse físicamente a los lugares donde se producían. Nacía entonces la sociedad red (Castells, 2011).

Son innumerables, y exceden con mucho el espacio de este trabajo, las transformaciones operadas en los distintos niveles de lo social causadas por este despliegue de fuerzas productivas y nuevos consu-

Basten algunas cifras para mostrar la magnitud del fenómeno. A finales de 2018 el $88 \%$ de los hogares españoles cuentan con al menos un ordenador. El 57\% con una tablet. Un 37\% con una smart tv. El 78\% un smartphone. El gasto medio por hogar en servicios TIC es de más de 65 euros al mes. El 82\% de los hogares cuenta con conexión a internet, con un $83 \%$ de personas que lo usan diariamente (ONTSI, 2019). 
mos. No obstante, en relación con la revisión realizada en los apartados anteriores, cabe resaltar algunas de ellas.

En primer lugar, este desarrollo pone aún más si cabe de manifiesto el valor del argumento de que las necesidades son el resultado de una relación social. Si durante el fordismo, con el auge de la norma del consumo de masas, el electrodoméstico o el vehículo privado se convierten en una necesidad casi primordial, en la era digital, dispositivos y acceso a la red juegan un papel similar. Además, a consecuencia de la personalización de contenidos (Parisier, 2017), el marketing y la publicidad están en condiciones de alcanzar un nivel de detalle de la información nunca visto. Sus mecanismos se refinan tratando de obtener atención constante en un contexto de "capitalismo de la atención" (Peirano, 2019). A la aparición de dispositivos siempre novedosos se une la promoción de una presencia cada vez más activa en la red (Van Dijk, 2016). Esto parece apoyar y consolidar la tendencia hacia un tipo de identidades sociales "errantes y borrosas" (Alonso, 2004, p. 36) que viven inmersas en un ciclo constante de autoproducción y autopromoción, del cual el selfie podría representar un ejemplo paradigmático (Sampedro, 2018).

Esto nos llevaría a la segunda cuestión propuesta anteriormente. Si ponemos en relación ambas esferas, consumo y producción, la omnipresencia de internet contribuye a desdibujar aún más las líneas entre ambos procesos. Pues si bien encontramos una serie de aspectos implicados en su desarrollo para los cuales sigue siendo necesaria la existencia de la gran industria fordista, -eso sí, ahora deslocalizada y con sus fases productivas fragmentadas y diseminadas por un territorio global- una parte creciente de sus contenidos, o de los bienes y servicios ofrecidos en su seno, son producidos como resultado de un proceso de consumo (Ritzer y Jurgenson, 2010; Rifkin, 2014). Para mostrar dos aspectos paradigmáticos de cómo estas cuestiones se problematizan aún más en la era digital, pasamos a exponer dos tipos de prácticas específicas, fijándonos especialmente en algunas consecuencias imprevistas que se darían como resultado de su extensión.

\section{Prosumidores colaborativos produciendo repu- tación}

Uno de los fenómenos crecientes gracias al desarrollo de internet queda recogido bajo el ambiguo y difuso término de sharing economy. No es el objetivo principal de este trabajo realizar una definición pormenorizada del fenómeno o perfilar con claridad sus límites; encontramos numerosa literatura dedicada principalmente a esta cuestión (Alonso, 2017; Botsman y Rogers, 2010; Comisión Europea, 2016; Gil, 2018; Gil, 2019; Gordo, De Rivera y Cassidy, 2016; Rifkin, 2014; Schor, 2014; Slee, 2016; Sundararajan, 2016; Taeihagh, 2017). Nuestro foco se pondrá sobre un aspecto fundamental para su desarrollo: la valora- ción de la transacción realizada en su seno como condición necesaria para favorecer el constante aumento de los intercambios (De Rivera, Gordo, Cassidy y Apesteguía, 2016; Möhlmann y Geissinger, 2018; Pick, 2012; Slee, 2016; Sundararajan, 2016). Conforme los espacios de interacción de las economías colaborativas desbordan el marco local, se hace cada vez más necesario articular sistemas que reduzcan las resistencias a participar en este tipo de mercados. Especialmente cuando el tipo de servicio prestado lleva asociado un elevado nivel de incertidumbre y supone una cierta vulnerabilidad. Por poner algunos ejemplos, abrir las puertas de tu casa a un desconocido, que en ocasiones está de paso o reside en otro país, relación en la que se basa Airbnb, puede tener nefastas consecuencias, tanto para el anfitrión (Arrington, 2011), como para el huésped (Gander, 2015). Un nivel de incertidumbre comparable al de viajar en un automóvil conducido por un particular, como sería el caso de Uber o Blablacar, donde la experiencia puede ser negativa para cualquiera de los participantes, estén en el lado del intercambio que estén (Uber, 2019).

Aunque podamos considerar que estas plataformas obtienen su beneficio en base a facilitar intercambios comerciales con fines de lucro, lo que intuitivamente las alejaría de poder ser consideradas colaborativas según el criterio de Schor (2014), también, y simultáneamente, podrían dar cabida a actividades poco lucrativas o no profesionalizadas. Esto evidenciaría la complejidad de las categorizaciones en este sentido y la dificultad para establecer tipologías suficientemente excluyentes, debido principalmente a que en el mismo diseño de la plataforma caben muchas prácticas diferentes (Gil, 2018): desde compartir los gastos de viaje hasta cambiar tu destino vacacional en función de la demanda en Blablacar. Desde alquilar puntualmente una habitación vacía hasta adquirir propiedades inmobiliarias y destinarlas al alquiler vacacional en Airbnb, por poner algunos ejemplos.

En todo caso, y para lo que nos interesa, en todas ellas encontramos un elemento común, el papel central jugado por la confianza para el buen funcionamiento de la plataforma al facilitar la realización de transacciones entre los distintos usuarios que alberga en su seno. El valor de la confianza como condición necesaria para facilitar transacciones no es una innovación propia de este ecosistema colaborativo. Ya para Luhman (1996) constituye una pieza clave de la sociabilidad. En el campo específico de los intercambios Hardin (1999) muestra cómo sirve para aumentar la cooperación entre individuos. En el mismo sentido parecen ir algunas evidencias presentadas por los integrantes de esa versión del capital social, para los cuales la confianza sería una cualidad cívica que actuaría como condición de posibilidad para mantener comunidades cohesionadas, entre los cuales Putnam (2002) podría considerarse su máximo exponente.

Además, en este contexto digital, esta capacidad de generar confianza interpersonal ha sido presentada como una de las mayores aportaciones de las economías colaborativas a la sociedad (Botsman y Rogers, 
2010; Sundararajan, 2016). Como ejemplo paradigmático, y a modo de resumen sumario de los fundamentos de esta pseudo ideología, encontramos unas declaraciones del cofundador y director ejecutivo de Airbnb, Brian Chesky, en las que afirma que gracias a la información que se añade al propio perfil en la plataforma "se elimina toda la fricción social debido a la falta de confianza (...) Tu reputación ahora es como tener una llave gigante que te permitirá abrir más y más puertas. [Los jóvenes] hoy no quieren ser dueños de esas puertas, pero querrán la llave que las desbloquee" (Friedman, 2014). La innovación estaría en los procedimientos empleados para su elaboración, consistentes en la valoración de las transacciones realizadas por los participantes. Como resultado, las sucesivas valoraciones que cada participante recibe acaban cristalizando en sistemas de reputación online, cuya relevancia para el buen funcionamiento de la plataforma es puesta de manifiesto por numerosos trabajos (De Rivera et al., 2016; Dujarier, 2016; Gil, 2018; Pick, 2012; Shor y Atwood-Charles, 2017; Slee, 2016; Sundararajan, 2016). Así, se crearía una imagen de confiabilidad que cada usuario va acumulando (Brown y Morgan, 2006) para facilitar la realización de futuros intercambios. Las puntuaciones obtenidas son el resultado de la valoración subjetiva y del grado de satisfacción entre los diferentes participantes, por ello se presentan como un sistema justo de atribución de responsabilidades en el que el intermediario, la plataforma, apenas influye en los resultados. Sin embargo, sus efectos son ambivalentes, mientras que por un lado proporciona al consumidor o consumidora la posibilidad de cierto empoderamiento ante posibles incumplimientos de los acuerdos, simultáneamente se incrementa el valor de la plataforma en sí sin que esta tenga que desarrollar trabajo alguno, institucionalizándose de este modo una cierta tiranía amparada bajo "estilos disciplinarios de gestión centralizados y ajenos a cualquier responsabilidad" (Slee, 2016). Esto termina por convertirse en un capital, en este caso a lo Bourdieu (Gil, 2019; Pick, 2012), que transmite información de cada vendedor y le permite posicionarse de manera diferencial en el mercado.

Podemos encontrar así criterios de valoración erráticos e inconsistentes, emitidos como resultados de infinidad de elementos subjetivos, incluso el estado de ánimo puntual del consumidor. Además de suponer barreras de entrada para nuevos usuarios que no cuentan con ese capital acumulado (Brown y Morgan, 2016), o de propiciar discriminaciones hacia participantes que no cuenten con un determinado tipo de capital (Edelman y Luca, 2014), además de que en numerosos casos el tratamiento de esta información es opaco para los participantes (Rosenblat y Stark, 2016). Las valoraciones pueden ser utilizadas para articular "modos algocráticos de organización" (Aneesh, 2009), por medio de los cuales ejercer un nuevo tipo de disciplinamiento difuso (Möhlmann y Geissinger, 2018; Rosenblat y Stark, 2016), encubierto bajo la apariencia de preservar la soberanía del consumidor. Lo fundamental para nuestro interés estaría en que la aportación del prosumidor (Ritzer y Jurgenson, 2010) inmerso en estas plataformas va un paso más allá de producir a la vez que consume. Mediante la valoración estaría proporcionando la información primaria que serviría para construir la arquitectura organizativa de la propia plataforma. De este modo, la plataforma externaliza buena parte del trabajo gerencial que requiere esta gestión, depositándola en manos de los participantes de las transacciones y limitándose tan solo a construir el algoritmo que sirve para gestionar y clasificar de manera automatizada esta información, dislocando más si cabe las dicotomías consumo-producción. Aparece entonces un nuevo tipo de trabajo latente que genera valor añadido y del cual se apropian las plataformas como mayores beneficiarios.

El valor generado por los sistemas de reputación construidos por los usuarios es traducido a datos, sumándose a la infinidad de datos proporcionados de manera activa y voluntaria -sobre gustos, preferencias, geolocalización, solvencia...-, asociados a los mismos procesos de intercambios (Möhlmann y Geissinger 2018), que junto a los metadatos (Llaneza, 2019), son capturados, gestionados y monetarizados para seguir impulsando un ciclo indefinido de crecimiento y monopolio de estas plataformas. Si bien el campo específico de la acción de las organizaciones mediadoras en la economía colaborativa es el de gestionar los intercambios, coexiste con y se retroalimenta de otro tipo de negocio que se impone en la web dedicado específicamente a explotar estos y otros tipos de datos.

\section{Produsarios produciendo contenidos y datos}

Dos compañías ocupan una situación dominante en este nuevo ecosistema: Google y Facebook. Ambas son pioneras y actores principales en el desarrollo de un modelo de negocio consistente en ofrecer productos y servicios, de manera aparentemente gratuita, como gancho principal con el que atraer usuarios. A cambio los participantes o usuarios de estas plataformas pagan con crecientes cantidades de datos (Llaneza, 2019), resultado de actividades "directamente productivas concebidas y practicadas como formas de ocio o de consumo" (Lara, 2018, p. 162). Actualmente los desarrollos e innovaciones de estas compañías suponen incrementar su facturación publicitaria. En el primer trimestre de 2016 Google obtenía por este medio el $89 \%$ de sus ingresos y Facebook más del 96\% (Srnicek, 2018). Unido esto al efecto red que contribuye a reforzar una tendencia casi monopolística supone que su valor no pare de crecer. Mientras Alphabet, la matriz de Google ocupa el cuarto puesto en cuanto a capitalización bursátil del mundo, con más de seiscientos mil millones de dólares, Facebook se sitúa en el séptimo lugar de ese ranking, con un valor superior a los trescientos mil millones de dólares, a fecha de 1 de enero de 2019 (Blog Bankinter. com, 2019). 
En el caso de Facebook los usuarios producen directamente los contenidos que atraen a su vez a otros usuarios "en un flujo de subjetividad y de despliegue de su socialidad en la red" (Lara, 2018, p. 167). Así, cuanta más gente está presente y activa en Facebook más sentido tiene permanecer en la red social. A ello se suman diseños ideados para propiciar un cierto grado de adicción explotando la motivación social de pertenecer y ser aceptados en las comunidades virtuales (Peirano, 2019, p. 32). En el caso de Google el acceso a un número creciente de fuentes de información secundaria producida por sus usuarios le proporciona datos que explotar y analizar (Zuboff, 2015). El dominio de smartphones con sistema operativo Android $^{4}$, el correo electrónico que se hace obligatorio para activar estos dispositivos, los navegadores de su propiedad o las búsquedas realizadas en su buscador, por poner ejemplos comunes, son las fuentes de las que extraer materia prima con las que alimentar la maquinaria. En todos estos casos estaríamos ante la capacidad desplegada por Google de extraer valor de actividades que ya han pasado a ser cotidianas y formar parte de la norma social. Junto al uso de cada vez más objetos conectados a la red, del crecimiento de la capacidad de almacenamiento y gestión de la información digitalizada o al vigor de los sistemas de inteligencia artificial, podemos atisbar un horizonte en el que sea posible "capitalizar las menores manifestaciones de la vida" (Sadin, 2018, p. 144), extendiéndose más allá de los propios actos de consumo consciente y alcanzando aspectos tan íntimos y aparentemente alejados de las esferas de la producción, el consumo o el trabajo como la calidad del sueño.

Aunque inicialmente la recopilación de datos iba dirigida a mejorar la experiencia de usuario (Parisier, 2017), su uso se ha dirigido principalmente a estimular el consumo mediante espacios publicitarios convencionales o comercializar los propios datos generados por los usuarios (Dujarier, 2016). Si bien, como venimos señalando, el valor de estas compañías reside en un ejercicio particular del negocio publicitario. Mediante estos procesos de recogida de datos alcanzan un nivel de detalle y granularidad de la información hasta ahora nunca antes conocido, permitiéndoles ser capaces de asignar mensajes publicitarios dirigidos a estimular el consumo de productos y servicios con un grado de segmentación y personalización sin igual. El conocimiento al detalle de las preferencias de sus usuarios permite difuminar aún más las fronteras entre deseo y necesidad, creando necesidades personalizadas resultado de explotar deseos muy particulares, aunque socialmente construidos en interacciones registradas por estas plataformas. Lo que parece especialmente relevante es que esta trazabilidad de las interacciones que permite establecer mapas personalizados del deseo y la necesidad, es a su vez obtenida mediante un conjunto de prácticas de consumo que son capitalizadas

A finales de 2018 el $81 \%$ de los smartphones y el $65 \%$ de las tablets en España utilizaban el sistema operativo Android, desarrollado por Google (ONTSI, 2019). y transformadas así en medios de producción. Entramos por tanto en un círculo de retroalimentación que dificulta enormemente establecer criterios claros acerca de dónde empieza cada uno de los procesos sociales que lo constituyen. Similar dificultad encontramos a la hora de conceptualizar estas aportaciones como trabajo productivo, es decir, como un proceso que genera valor y que es el resultado de una práctica de consumo. Mientras que Srnicek (2018), adoptando una visión marxista clásica, entiende que, al carecer de las presiones competitivas características a las funciones productivas en el sistema capitalista, esto no puede considerarse trabajo, encontramos en Lara (2018) razones para poder incluir la producción de contenidos y las interacciones en el ecosistema digital bajo la rúbrica de trabajo, si bien considerándolo como integrante de una categoría particular denominada como bioproducción (Lara, 2018, p. 168). Para reforzar esta conceptualización emplea el término produsuario, resultado de la agregación de productor y usuario, "por el carácter productivo de su actividad en la red social" (Lara, 2018, p. 164). Cabe señalar que existen evidencias de que hay elementos del propio diseño de las redes sociales especialmente orientados a fomentar la adicción (Peirano, 2019). A ello contribuye la extensión de la idea del "empresario de sí mismo" (Foucault, 2007, p. 265), que aplicada a este campo actuaría como una presión competitiva añadida impulsando la presencia activa y constante en redes sociales como un mecanismo más de creación y apuntalamiento de la imagen de marca de esa autoempresa, regida principalmente por el principio de popularidad (Van Dijk, 2016).

Por su parte, desde la perspectiva de la sociología del consumo esta actividad queda claramente dentro de su campo. Es realizada principalmente durante el tiempo de ocio y orientada a satisfacer una serie de necesidades de tipo social. Eso sí, un tipo de consumo que contribuye a la generación de valor en sí mismo, en forma de datos o contenidos que atraen la atención generando así más datos, que luego han de ser procesados para mejorar su productividad. Como rasgo especialmente particular de estas actividades, a partir de la extensión del ethos neoliberal, las propias pautas de consumo en redes sociales desde la perspectiva del produsuario se alejan de ser meras satisfacciones en sí mismas. Por el contrario, encontramos su más pleno sentido en buena parte de ellas si les aplicamos el filtro de la racionalidad instrumental propia de ese ethos. Así, consumir determinados productos, estudiar en determinadas universidades, acudir a ciertos espectáculos, vivir en determinados lugares o viajar a otros, por poner solo algunos ejemplos, una vez que son empaquetados para su difusión en redes sociales pueden ser interpretados en términos de inversión en uno mismo. De este modo se establecen contactos y se crean redes cuya aspiración última es la de la propia promoción de individuo como una marca en sí, como un producto más que adquiere un especial valor. Sería entonces un consumo productivo en sí 
mismo. Un nexo que une todas estas prácticas digitales que se han mostrado estaría en que en su desarrollo unas se sirven de otras de manera multiplicadora y amplificadora. En un contexto de merma de ingresos obtenidos por vías convencionales, como era el trabajo formal en la era fordista, particularmente centrado en los sectores sociales más jóvenes y dinámicos, apoyado en un proceso globalizador, el efecto demostración ampliamente difundido en redes sociales actúa como impulsor de un conjunto de consumos que ahora se podrían hacer con menores desembolsos gracias a capitales relacionales obtenidos en redes de intercambio. Asistiríamos entonces a un cambio que, partiendo de nuevas "prácticas de consumo atraviesa la estructura social en su conjunto y necesita una reorganización, simbólica y práctica del conjunto de los campos en los que construyen las clases sociales" (Alonso, 2005, p. 189). Lo que vendría a suponer un campo de nuevos espacios de conflicto y dominación impulsados desde la total dislocación y reconfiguración de las esferas sociales de consumo y producción, de la noción de necesidad, trastocando también los límites de aquello que podemos considerar trabajo, vínculo tradicional entre estas cuestiones. Para ello la sociología del consumo, como la sociología en general, debe incluir problematizando adecuadamente todas estas cuestiones novedosas y muchas más que son susceptibles de aparecer.

\section{Reflexiones finales}

Hemos tratado de mostrar cómo la sociología del consumo jugó un papel fundamental a la hora de identificar algunos puntos oscuros sobre este hecho social que desde una perspectiva economicista más estrecha se daba casi por naturalizado. Particularmente nos hemos centrado en la problematización de la misma noción de necesidad y las conexiones que existen para el propio desarrollo del sistema capitalista entre producción y consumo, con los procesos políticos que se hicieron necesarios desplegar para mantenerlos ligados. La entrada en un ciclo de crisis sucesivas supuso el desarrollo de nuevas formas productivas y de nuevos modos de consumo. Algunos de los cuales fueron impulsados por retóricas liberalizadoras y democratizadoras. Las economías colaborativas o economías del compartir se inscriben en sus inicios en el campo del consumo consciente, de la sostenibilidad, del acceso frente a la propiedad..., pudiendo ser consideradas como una expresión de un movimiento social (Alonso, 2017). Google, por su parte, puso infinidad de información al alcance de un clic, facilitando la presencia en el nuevo ecosistema digital de numerosos actores en función de relevancia e intereses. Facebook permitió en sus inicios ampliar las fuentes de información y propició la sociabilidad en red, llegando incluso a jugar un papel relevante como infraestructura comunicativa y organizacional al servicio de numero- sas protestas sociales y expresiones de descontento (Castells, 2013).

Sin embargo, en su despliegue, como consecuencia de la necesidad de generar beneficios, tanto Google como Facebook, como las plataformas que proporcionaban soporte para incrementar la escala de las economías colaborativas, han ido provocando consecuencias inicialmente imprevistas. Hemos tratado de mostrar que los sistemas de reputación online podrían estar fomentando procedimientos de gestión algorítmica que ejercerían un disciplinamiento difuso de los participantes. Estos sistemas se alimentarían básicamente del trabajo de los participantes en intercambios, el cual es a su vez su capital principal. Con ello se desdibujan aún más las líneas entre productor y consumidor que lo que recogía el término de prosumidor (Ritzer y Jurgenson, 2010). Para el caso de Google o Facebook la trasmutación de posiciones es tal que se hace necesario acuñar un nuevo término, algo que ya hace Lara (2018) con el concepto de produsuario. Con estos ejemplos parece más evidente que consumo y producción en la era digital han desbordado por completo el marco de comprensión en el que estaban inscritos. Los usuarios son impelidos a generar estructuras normativas difusas que vengan a sustituir marcos regulatorios claros en un tiempo donde se hace dominante la retórica de la desregulación. Además, toda su actividad en la red, que se vuelve ubicua, es capturada y puesta en valor gracias a los cambios de pautas de uso y a una transformación tecnológica en la que emerge un nuevo campo semántico plagado de términos como machine learning, big data, aprendizaje profundo o Inteligencia Artificial..., como punta de lanza de una justificación determinista tecnológica para naturalizar nuevos procesos de acumulación.

A su vez todo esto tiene lugar en un contexto de expansión del campo de las necesidades sin parangón. Así, obtener información en tiempo real, desplazarse cada vez más rápido y a cada vez más lugares o permanecer integrado en redes sociales de familia, amistades, laborales..., recibiendo actualizaciones y comunicaciones instantáneas, son solo algunos de los ejemplos de nuevas necesidades cada vez más imperiosas a las que se hace extremadamente difícil renunciar, so pena de quedar desconectado en un mundo a su vez cada vez más conectado. Siendo, por tanto, un ejemplo paradigmático de creación social de las necesidades, donde lo social es puramente relacional, al estilo, una vez más, de Bourdieu.

Por ello, la propuesta que se plantea hacia el campo de la sociología del consumo es la de adaptar el enfoque y ampliar el marco de observación para incluir en el propio ámbito de investigación este conjunto de nuevas prácticas como prácticas de consumo que son, haciéndolo además atendiendo a las diferentes perspectivas y consecuencias que se despliegan de las mismas, de las que estas que se presentan aquí constituyen meros ejemplos que no agotan en absoluto esta perspectiva. 


\section{Referencias}

Aglietta, M. (1979). Regulación y crisis del capitalismo. La experiencia de los Estados Unidos. México: Siglo XXI.

Aneesh, A. (2009). Global Labor: Algocratic Modes of Organization. Sociological Theory 27:4 December, 347-370.

Alonso, L.E. (1986). La producción social de la necesidad. Economistas, 4 (18), 26-31.

Alonso, L.E. (2004). Las políticas del consumo: transformaciones en el proceso de trabajo y fragmentación de los estilos de vida. Revista Española de Sociología 4, 7-50

Alonso, L.E. (2005). La era del consumo. Madrid: Siglo XXI.

Alonso, L.E. (2017). Consumo colaborativo: las razones de un debate. Revista Española de Sociología, 26 (1), 87-95. http://dx.doi.org/10.22325/fes/res.2017.4

Arribas, J.M. (Coord.) (2013). Sociología del consumo e investigación de mercados. Madrid: UNED.

Arrington, M. (2011, 27 julio). The moment of truth for Airbnb as user's home is utterly trashed. TechCrunch.com. Recuperado de: https://techcrunch.com/2011/07/27/the-moment-of-truth-for-airbnb-as-users-home-is-utterly-trashed/

Beck, U. (1998). La sociedad del riesgo. Hacia una nueva modernidad. Barcelona: Paidós.

Blog Bankinter.com (2019, 2 enero). TOP compañías que más valen en bolsa. Recuperado de: https://blog.bankinter.com/ economia/-/noticia/2019/1/2/empresas-mas-valen-bolsa

Bourdieu, P. (2012). La distinción. Criterio y bases sociales del gusto. Barcelona: Taurus.

Botsman, R., y Rogers, R. (2010). What's mine is yours: The Rise of Collaborative Consumption. Nueva York: Harper Collins.

Braverman, H. (1975). Trabajo y capital monopolista. México: Editorial Nuestro Tiempo.

Briggs, A. y Burke, P. (2002). De Gutenberg a Internet. Una historia social de los medios de comunicación. Madrid: Taurus.

Brown, J., y Morgan, J. (2006). Reputation in online markets: Some negative feedback (Unpublished paper). University of California, Berkeley. Recuperado de: https://pdfs.semanticscholar.org/ce48/61329f55528ce78c2a9812e67d20cead 1ec9.pdf

Carr, N. (2018). Superficiales. ¿Qué está haciendo Internet con nuestras mentes? Barcelona: Penguin Random House.

Castells, M. (2011). Comunicación y poder. Madrid: Alianza.

Castells, M. (2013). Redes de indignación y esperanza. Madrid: Alianza.

Comisión Europea (2016). Comunicación de la Comisión al Parlamento Europeo, al Consejo, al Comité Económico y Social Europeo y al Comité de las Regiones. Una Agenda Europea para la economía colaborativa, 356 final. Recuperado de https://eur-lex.europa.eu/legal-content/ES/TXT/PDF/?uri=CELEX:52016AE3545\&from=ES

Dardot, P., y Laval, C. (2013). La nueva razón del mundo. Ensayo sobre la sociedad neoliberal. Barcelona: Gedisa.

De Rivera, J., Gordo, A., Cassidy, P., y Apesteguía, A. (2016). A netnographic study of P2P collaborative consumptionplatforms' user interface and design. Environmental Innovation and Societal Transitions 23 11-27. https://doi. org/10.1016/j.eist.2016.09.003

Dujarier, M-A. (2016, 18 enero). "Digital labor, travail du consommateur: ¿quels usages sociaux du numérique?” Ina Global, Magazine numérique international sur les industries créatives et les médias del Institut National de l'Audiovisuel (Francia). Recuperado de: https://larevuedesmedias.ina.fr/digital-labor-travail-du-consommateur-quels-usages-sociaux-du-numerique

Edelman, B., Luca, M. (2014). Digital discrimination: the case of Airbnb.com. Harvard Business Scholl. Working Paper. Recuperado de: https://www.hbs.edu/faculty/Publication\%20Files/Airbnb_92dd6086-6e46-4eaf-9cea-60fe5ba3c596. pdf

Foucault, M. (2007). El Nacimiento de la biopolítica. Curso en el Collège de France (1978-1979). Buenos Aires: Fondo de Cultura Económica.

Friedman, T.L. (2014, 19 julio). And Now for a Bit of Good News . . The New York Times. Recuperado de https://www. nytimes.com/2014/07/20/opinion/sunday/thomas-1-friedman-and-now-for-a-bit-of-good-news.html?auth=linkedgoogle1tap

Gander, K. (2015, 16 agosto). Airbnb safety: sexual assault allegations against host in Madrid raise questions about website's responsibilities. The Independent. Recuperado de : https://www.independent.co.uk/travel/news-and-advice/ airbnb-safety-sexual-assault-allegations-against-host-in-madrid-raise-questions-about-websites-10457992.html

Gil García, J. (2018). ¿Qué son las economías colaborativas? Papeles de Relaciones Ecosociales y Cambio Global, núm. 141, primavera, 49-62.

Gil García, J. (2016). Economías colaborativas y crisis del capitalismo: un análisis a través de la prosumición. En Ciberpolítica: Gobierno abierto, redes, deliberación, democracia (R. Cotarelo y J. Gil García, pp. 167-188). Madrid: Instituto Nacional de Administración Pública.

Goldthorpe, J. H. (2012). De vuelta a la clase y el estatus: por qué debe reivindicarse una perspectiva sociológica de la desigualdad social. Revista Española de Investigaciones Sociológicas, 137, 43-58.

Gordo, A. J., de Rivera, J., y Cassidy, P. (2016). La economía colaborativa y sus impactos sociales en la era del capitalismo digital. En Ciberpolítica: Gobierno abierto, redes, deliberación, democracia (R. Cotarelo y J. Gil García, pp. 189208). Madrid: Instituto Nacional de Administración Pública.

Harvey, D. (2007). Breve historia del neoliberalismo. Madrid: Akal. 
Hardin, R. (1999). Do we want trust in government? En Democracy and Trust, (M. E. Warren, pp. 22-41). Cambridge, Cambridge University Press.

Keen, A. (2016). Internet no es la respuesta. Barcelona: Catedral.

Lara, A.L. (2018). Facework: trabajo digital, redes sociales y nueva servidumbre. Sociología del Trabajo, nº93, 159-180. https://doi.org/10.5209/STRA.61795

López de Ayala, M. C. (2004). El análisis sociológico del consumo. Una revisión histórica de sus desarrollos teóricos. Sociológica. Revista de pensamiento social, 5, 161-188.

Llaneza, P. (2019). Datanomics. Todos los datos que das sin darte cuenta y todo lo que las empresas hacen con ellos. Barcelona: Deusto.

Luhman, N. (1996). Confianza. Barcelona: Anthropos Editorial.

Marshall, T.H. (1997). Ciudadanía y clase social. Revista Española de Investigaciones Sociológicas. 79/97. $297-344$.

Mason, P. (2016). Postcapitalismo. Hacia un nuevo futuro. Barcelona: Paidós.

Mayer-Schönberger, V., y Cukier, K. (2013). Big data. La revolución de los datos masivos. Madrid: Turner Publicaciones.

Mazzucato, M. (2014). El estado emprendedor. Barcelona: RBA.

Möhlmann, M., y Geissinger, A. (2018). Trust in the Sharing Economy: Platform-Mediated Peer Trust. En The Cambridge Handbook of the Law of the Sharing Economy (N. Davidson, M. Finck, y J. Infranca (Eds) pp. 27-37). Cambridge: Cambridge University Press.

Morozov, E. (2018). Capitalismo Big Tech. Madrid: Enclave de Libros.

Naredo, J. M. (2015). La economía en evolución. Madrid: Siglo XXI.

ONTSI (2019). La sociedad en red. Transformación digital en España. Informe Anual 2018. Madrid: ONTSI. http://doi. org/10.30923/1989-7424-2019.

Ortí, A. (1986). La apertura y el enfoque cualitativo o estructural: la entrevista abierta y la discusión de grupo. En El análisis de la realidad social. Métodos y Técnicas de investigación. (M. García Ferrando, J. Ibáñez y F. Alvira, pp. 171204) Madrid: Alianza Universidad Textos.

Parisier, E. (2017). El filtro burbuja. Cómo la red decide lo que leemos y lo que pensamos. Barcelona: Taurus.

Peirano, M. (2019). El enemigo conoce el sistema. Barcelona: Penguin Random House.

Pick, F. (2012). Building Trust in Peer-to-Peer Marketplaces: An Empirical Analysis of Trust Systems for the Sharing Economy. Bachelor Thesis Communication Department Zeppelin University.

Polanyi, K. (2003). La gran transformación. Los orígenes políticos y económicos de nuestro tiempo. México: Fondo de Cultura Económica.

Putnam, R. (2002). Solo en la bolera. Barcelona: Galaxia Gutenberg.

Rifkin, J. (2014). La sociedad de coste marginal cero. El internet de las cosas, el procomún colaborativo y el eclipse del capitalismo. Barcelona: Paidós.

Ritzer, G. y Jurgenson, N. (2010). Production, Consumption, Prosumption. The nature of capitalism in the age of the digital 'prosumer'. Journal of Consume Culture, Vol 10(1), 13-36 1469-5405 https://doi.org/10.1177/1469540509354673

Rosenblat, A. y Stark, L. (2016). Algorithmic Labor and Information Asymmetries: A Case Study of Uber's Drivers. International Journal of Communication 10, 3758-3784.

Sadin, É. (2018). La siliconización del mundo. Buenos Aires: Caja Negra.

Sampedro, V. (2018). Dietética digital para adelgazar al gran hermano. Barcelona: Icaria Editorial.

Schor, J. (2014). Debating the Sharing Economy. Great Transition Initiative. Recuperado de: https:/greattransition.org/ publication/debating-the-sharing-economy

Schor, J., y Attwood-Charles, W. (2017). The "sharing" economy: labor, inequality, and social connection on for profit platforms. Sociology Compass.11: e12493. https://doi.org/10.1111/soc4.12493

Slee, T. (2016). Lo tuyo es mío. Contra la economía colaborativa. Barcelona: Taurus.

Srnicek, N. (2018). Capitalismo de plataformas. Buenos Aires: Caja Negra.

Standing, G. (2013). El precariado. Una nueva clase social. Barcelona: Pasado y Presente.

Sundararajan, A. (2016). The sharing economy: The end of employment and the rise of crowd-based capitalism. Boston: MIT Press.

Taeihagh, A. (2017). Crowdsourcing, Sharing Economies and Development. Journal of Developing Societies, Vol 33(2): 191-222. https://doi.org/10.1177/0169796X17710072

UBER (2019). 2017-2018 US Safety Report. Recuperado de https://www.uber-assets.com/image/upload/v1575580686/ Documents/Safety/UberUSSafetyReport_201718_FullReport.pdf

Van Dijck, J. (2016). La cultura de la conectividad: Una historia crítica de las redes sociales. Buenos Aires: Siglo XXI.

Veblen, T. (2004). Teoría de la clase ociosa. Madrid: Alianza Editorial.

Zuboff, S. (2019). The Age of Surveillance Capitalism: The Fight for a Human Future at the New Frontier of Power, London: Profile Books.

Zuboff, S. (2015). Big other: surveillance capitalism and the prospects of an information civilization. Journal of Information Technology 30, 75-89. https://doi.org/10.1057/jit.2015.5 